\title{
Effect of Weather Variables on Wheat Yield by Different Stages of Wheat through Box Plot Design
}

\author{
Subhash Kumar ${ }^{1 *}$, S.P. Singh, Mahesh Kumar ${ }^{1}$ and Abdus Sattar ${ }^{2}$ \\ ${ }^{1}$ Department of Statistics, Mathematics and Computer Application \\ ${ }^{2}$ Agro- meteorology Division \\ Dr. Rajendra Prasad Central Agricultural University, Pusa-848125, (Bihar), India \\ *Corresponding author
}

\section{A B S T R A C T}

\section{Keywords}

Climate change,

Wheat yield,

Weather variable,

Box Plot, Effect of

weather on yield

Article Info

Accepted:

18 April 2018

Available Online:

10 May 2018
Present study examines the effect of climatic factor e.g. Temperature (Maximum and Minimum), Relative humidity (Morning and Evening), Evaporation and Rainfall variation on the yield of different stages of wheat in Samastipur district of Bihar by using Box plot method. The data of wheat yield of 29 Years (1984-2013) was taken from Department of Agricultural Economics, RAU, Pusa and Weather Variables (1984-2013) was taken from Agro-metrology Unit, RAU, Pusa. Box plot will used to estimate the effect of climate variables on the stages of wheat yield. At tillering, dough and maturity stages, morning relative humidity was identified as the most important variable in explaining the yield variability.

\section{Introduction}

Evidently climate change is being realized in every walk of our life. Palpable impact is seen on growth and development, water use and productivity of major crops including wheat. Recently much attention has been given to the effects of climate change on agricultural output, because of the relevance of agriculture to the world economy, and the sensitivity of crop yields to climate conditions. Climate change impacts on India can have far-reaching consequences, as well; India is the world's second largest producer of agricultural outputs, and any changes in production due to climate change could materially impact global agricultural imports and exports. Agriculture is the most vulnerable sector to climate change. Agriculture productivity is being affected by a number of factors of climatic change including rainfall pattern, temperature, relative humidity, evaporation, changes in sowing and harvesting dates, water availability, and evapo-transpiration4 and land suitability. All these factors can change yield and agricultural productivity. The impact of climate change on agriculture is many folds including diminishing of agricultural output 
and shortening of growth period for crops. Countries lying in the tropical and sub tropical regions would face callous results, whereas regions in the temperate zone would be on the beneficial side. Although the climate change in some areas of the world, particularly the areas located within the northern widths above 55, will have positive effects on agricultural production (Ewert et al., 2005), but the negative impacts of these changes will be so severe in hot and dry areas (Parry et al., 2004), so in developing countries the rise in temperature and the decrease in rainfall have been more severe and moreover the frequency and intensity of the occurrence of rare climatic phenomena (drought, heat, coldness and flood) will also be intensified (IPCC, 2007). Undoubtedly, any change in climatic condition will affect the agricultural production systems of the world. Mall and Singh (2000) observed that small changes in the growing season temperature over the years appeared to be the key aspect of weather affecting yearly wheat yield fluctuations. Pathak et al., (2003) concluded that the negative trends in solar radiation and an increase in minimum temperature, resulting in declining trends of potential yields of wheat in the Indo-Gangetic plains of India. Selvaraju (2003) analyzed the relationship between Indian Summer Monsoon Rainfall (SMR) and food grain production in India. $\mathrm{He}$ found that the inter-annual variations are closely related. However, the magnitude of change in food grain production is smaller than the rainfall. Recent trends of a decline or stagnation in the yield of rice-wheat cropping system in Indo- Gangetic plain and north western India have raised serious concern about the regions food supply (Aggarwal et al., 2000; Pathak et al., 2003). Easterling et al., (2007) looked at studies that made quantitative projections of climate change impacts on food security. The first was that climate change would likely increase the number of people at risk of hunger compared with reference scenarios with no climate change. In 2006, the global estimate for the number of people under nourished was 820 million (FAO, 2011). This study aims to contribute to assessing how changing pattern of weather variables have affected the yields of major crops in India, over a 29 year time period from 1984-2013.

\section{Materials and Methods}

This research deals with methods, procedures and measurement techniques followed for carrying out the research work entitled "statistical analysis of wheat yield and climatic change in Samastipur district, Bihar". The present study has been carried out to focus on the overall impact of climate change on the wheat yield.

The methodology includes:

1. Locale of the study

2. Data and variables

3. Various statistical tools

\section{General description of the study area}

The study was carried out in Samastipur district of Bihar in India. This is situated in Agro- climatic zone I (Northern West). The traditional agricultural practice is prevalent in this district. Then latitude and longitude is $25^{\circ}$ $51^{\prime} 47.48^{\prime \prime} \mathrm{N}$ and $85^{\circ} 46^{\prime} 48.04 \quad 0^{\prime \prime} \mathrm{E}$ respectively. It is situated at an elevation of about $52 \mathrm{~m}$ above mean sea level. The climate of the site is characterized by hot and humid summers and cold winters with an average rainfall of $1200 \mathrm{~mm}, 70$ percent $(941 \mathrm{~mm})$ of which occurs during July -September and average temperature is maximum $36.6^{\circ} \mathrm{C}$ and minimum temperature is $7.7^{\circ} \mathrm{C}$. Frequent droughts and floods are common in the region.

\section{Data and variables}

Wheat productivity data 1984-2013 is collected from Dept. of Agricultural 
Economics, RAU, Pusa, Samastipur, Bihar on wheat productivity. We consider the average amount of wheat productivity in tones /hectare with the direct impact of climatic variables on wheat yield. The data regarding the climatic variables is collected from the Agrometeorology Unit, RAU, Pusa, Samastipur, Bihar.

\section{Following are the climatic factor and their} units which are taken in this research

1. Maximum temperature $\left({ }^{\circ} \mathrm{C}\right)$

2. Minimum Temperature $\left({ }^{\circ} \mathrm{C}\right)$

3. Relative Humidity (morning) $(\%)$

4. Relative Humidity (evening) (\%)

5. Rainfall (mm)

6. Evaporation $\left(\mathrm{mm} / \mathrm{m}^{2}\right)$

Sowing time of wheat is mid of November i.e. $15^{\text {th }}$ Nov- $20^{\text {th }} \mathrm{Nov}$ and harvesting time is start from first week of April.

\section{Box plots}

The box-and-whisker plot is an exploratory graphic, created by John W. Tukey, used to show the distribution of a dataset (at a glance). Think of the type of data you might use a histogram with, and the box-and-whisker (or box plot, for short) could probably be useful. In its simplest form, the box plot presents five sample statistic - the minimum, the lower quartile, the median, the upper quartile and the maximum - in a visual display. The box of the plot is a rectangle which encloses the middle half of the sample, with an end at each quartile. The length of the box is thus the inter quartile range of the sample. The other dimension of the box does not represent anything in particular. A line is drawn across the box at the sample median. Whiskers sprout from the two ends of the box until they reach the sample maximum and minimum. The crossbar at the far end of each whisker is optional and its length signifies nothing. The following diagram shows a dot plot of a sample of 20 observations (actual sample values used in the display) together with a box plot of the same data.

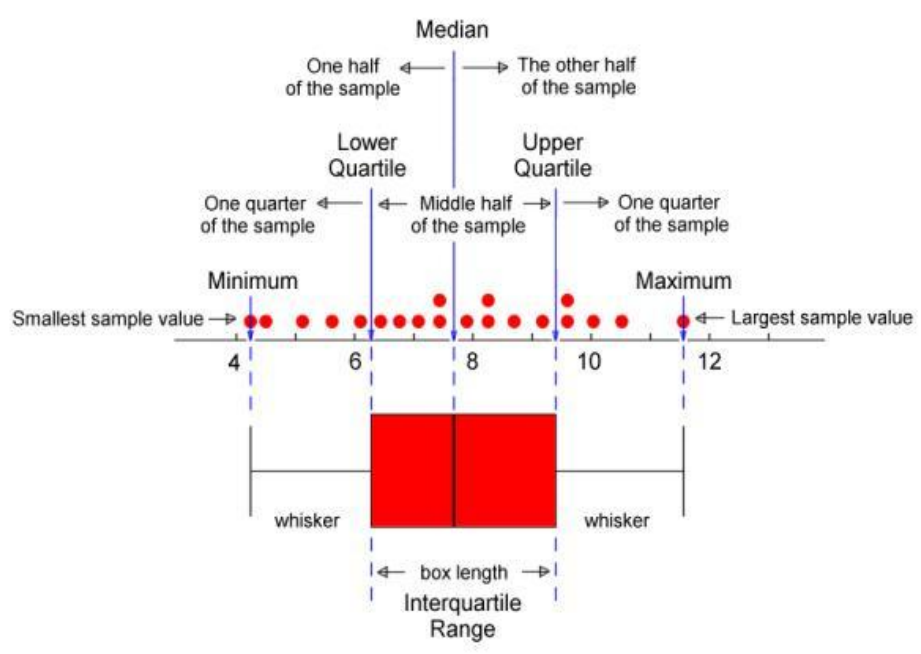

Although box plots can be drawn in any orientation, most statistical packages seem to produce them vertically by default, as shown on the right, rather than horizontally. The length of the box becomes its height. The width across the page signifies nothing.

Much more can be read from a box plot than might be surmised from the simplistic method of its construction, particularly when the box plots of several samples are lined up alongside one another (Parallel Box plots). The box length gives an indication of the sample variability and the line across the box shows where the sample is centered. The position of the box in its whiskers and the position of the line in the box also tell us whether the sample is symmetric or skewed, either to the right or left. For a symmetric distribution, long whiskers, relative to the box length, can betray a heavy tailed population and short whiskers, a short tailed population. So, provided the number of points in the sample is not too small, the box plot also gives us some idea of the "shape" of the sample, and by implication, the shape of the population from which it was drawn. This is all important when considering 
appropriate analyses of the data. The box plots produced by statistical packages are rarely as described above. An attempt is made to alert for the sample values which may be unusually removed from the bulk of the data. These sample values are represented variously as circles or asterisks beyond the bounds of the whiskers. The whiskers thus do not extend to the minimum and maximum of the sample, but to the smallest and largest values inside a "reasonable" distance from the end of the box. This can considerably alter the whisker length of the plot. A highly skewed sample, for example, may appear to be reasonably symmetric in its box and whiskers with many values flagged as unusual beyond the whisker on one side. When interpreting these box plots, it is a good idea to convert them to the simple form, by imagining the whiskers extend to the furthermost extreme points. The extra information provided by the flagging process enables you to distinguish between a truly skewed sample, and one whose apparent skewness is attributable to a single point at some remove from the rest of the data. Such a point or points may be an outlier; perhaps a measurement or data entry error, or a refugee from another population.

\section{Results and Discussion}

Effect of weather variables on wheat yield at its different stages

\section{Maximum temperature}

Figure 1 shows the Box Plot of Maximum Temperature at different growth Stages. For a symmetric distribution, long whiskers, relative to the box length, can betray a heavy tailed population and short whiskers, a short tailed population. In this figure, Maximum temperature $\left(\mathrm{T}_{7} \mathrm{Max}\right)$, Maximum temperature $\left(\mathrm{T}_{3}\right.$ Max) have heavy tailed variable at stage seven and a short tailed variable is at Maximum temperature $\left(\mathrm{T}_{2}\right.$. Max $)$. It means the maximum variation of Maximum temperature at node stage and dough stage and minimum variation of maximum temperature at Stage 2 . Dots represent outliers. Outliers at node stage and milk stage beyond the bounds of the whiskers are more than the normal and seedling emergence stage, boot stage and maturity stage has less than normal.

\section{Minimum temperature}

Figure 2 shows the Box Plot of Minimum temperature at different growth stages. Minimum temperature $\left(\mathrm{T}_{8} \cdot \mathrm{min}.\right)$, Minimum temperature $\left(\mathrm{T}_{1} \cdot \mathrm{min}\right)$ has heavy tailed variable at maturity stage and seedling emergence stage and a short tailed variable is at Minimum temperature $\left(\mathrm{T}_{3} \cdot \mathrm{min}\right)$ and $\left(\mathrm{T}_{5} \cdot \mathrm{min}\right)$. It means the Maximum variation of Minimum temperature maturity stages and seedling emergence stage and Minimum variation of Minimum temperature at node stage and ear head emergence. Dots represent outliers. Outliers at boot stages and ear head emergence which shows that the beyond the bounds of the whiskers is more than the normal and at node stage and dough stage has less than normal.

\section{Relative humidity in morning}

Figure 3 shows the Box Plot of Relative Humidity in Morning at different growth stages. Relative Humidity in Morning (RH17.), Relative Humidity in Morning (RH1-8.) has heavy tailed variable at dough stage and maturity stage and a short tailed variable is at Relative Humidity in Morning (RH1-5.) and (RH1-4.).

Dots represent outliers. Outliers at milk stage which shows that the beyond the bounds of the whiskers is more than the normal and at seedling emergence stage, tillering stage, node stage, ear head emergence and boot stage has less than normal. 
Fig.1 Box plot of maximum temperature $\left({ }^{\mathrm{O}} \mathrm{C}\right)$ at different growth stages

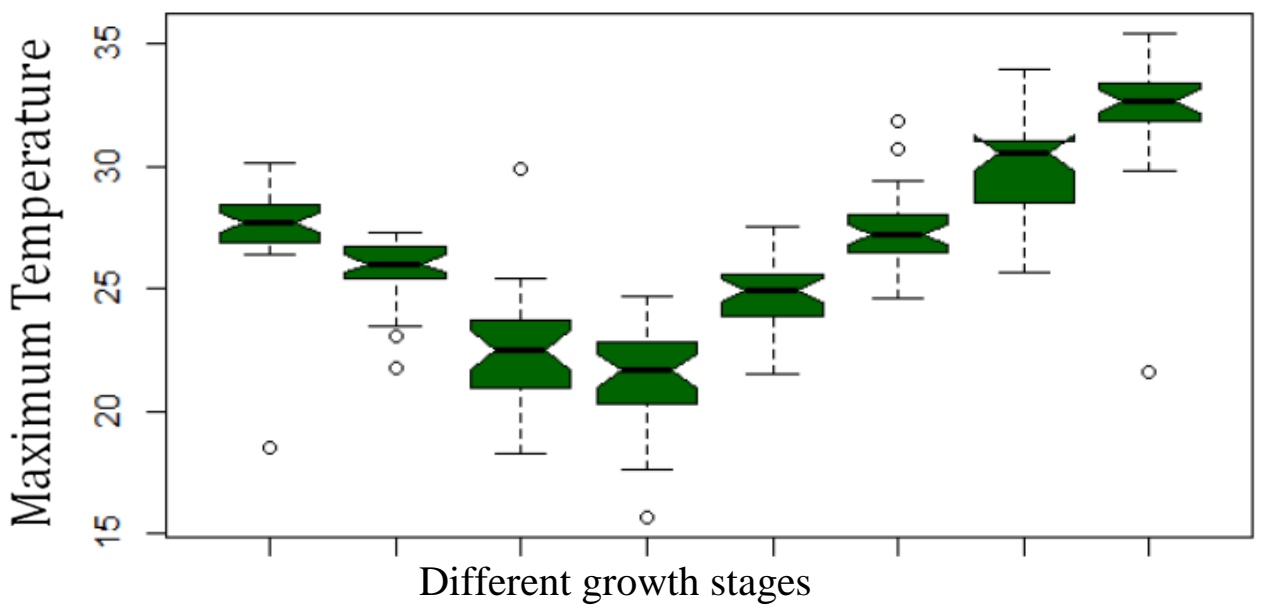

Fig.2 box plot of minimum temperature $\left({ }^{\circ} \mathrm{C}\right)$ at different growth stages

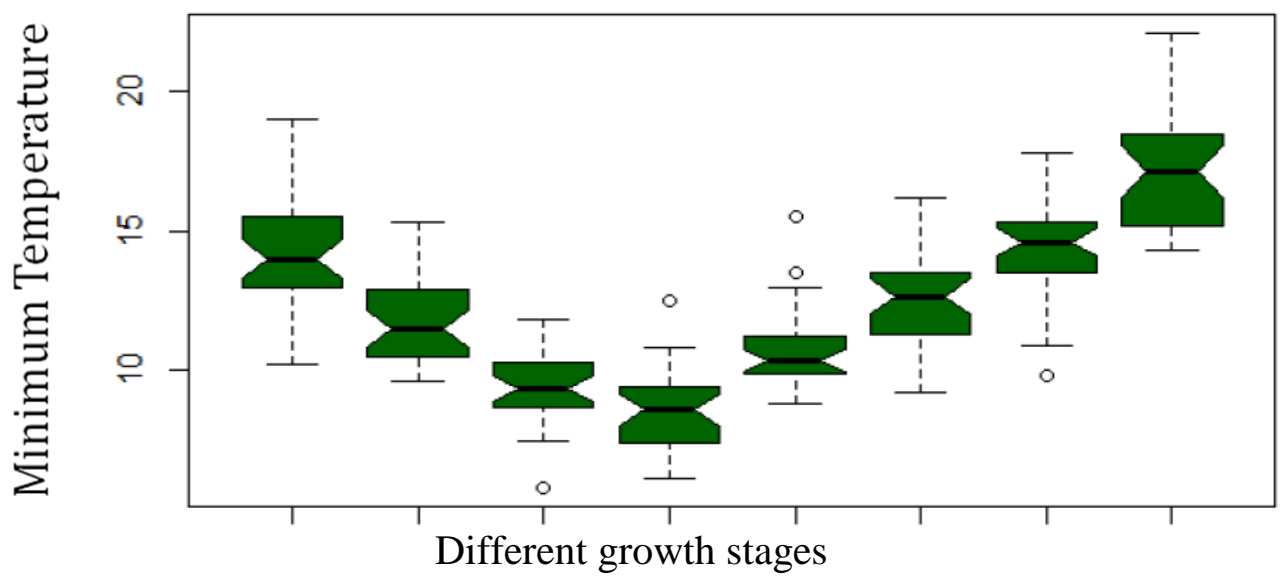

Fig.3 Box plot of relative humidity (morning) at different growth stages

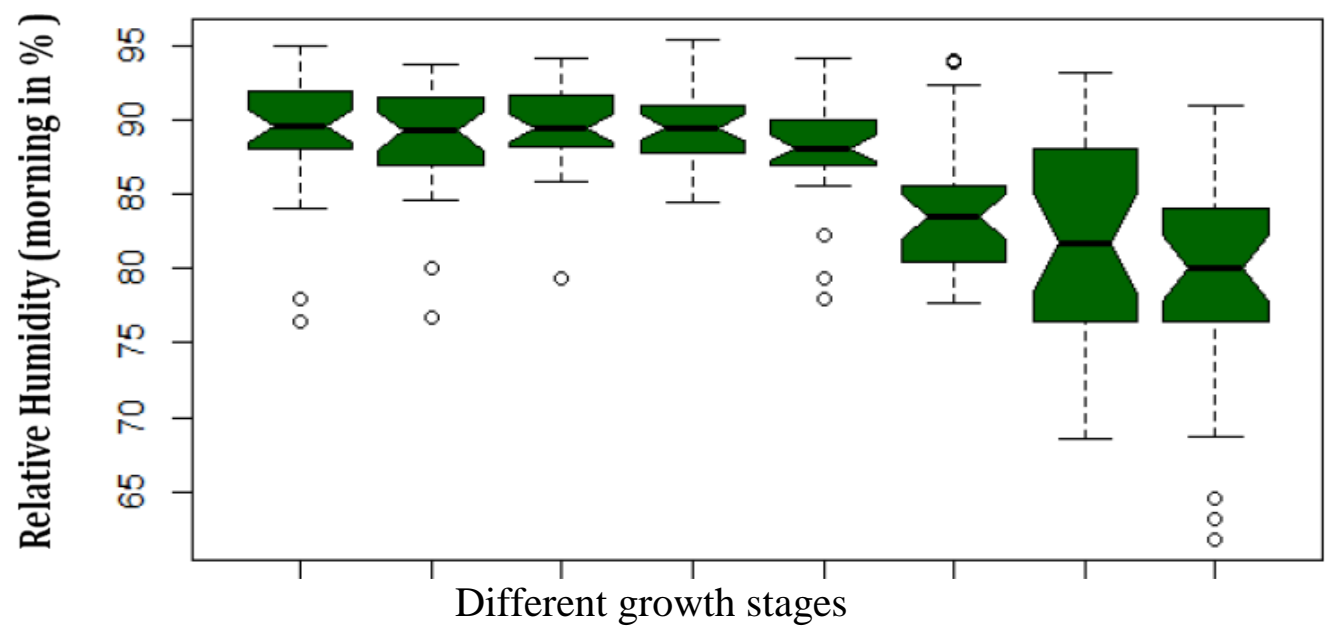


Fig.4 Box plot of relative humidity (evening) at different growth stages

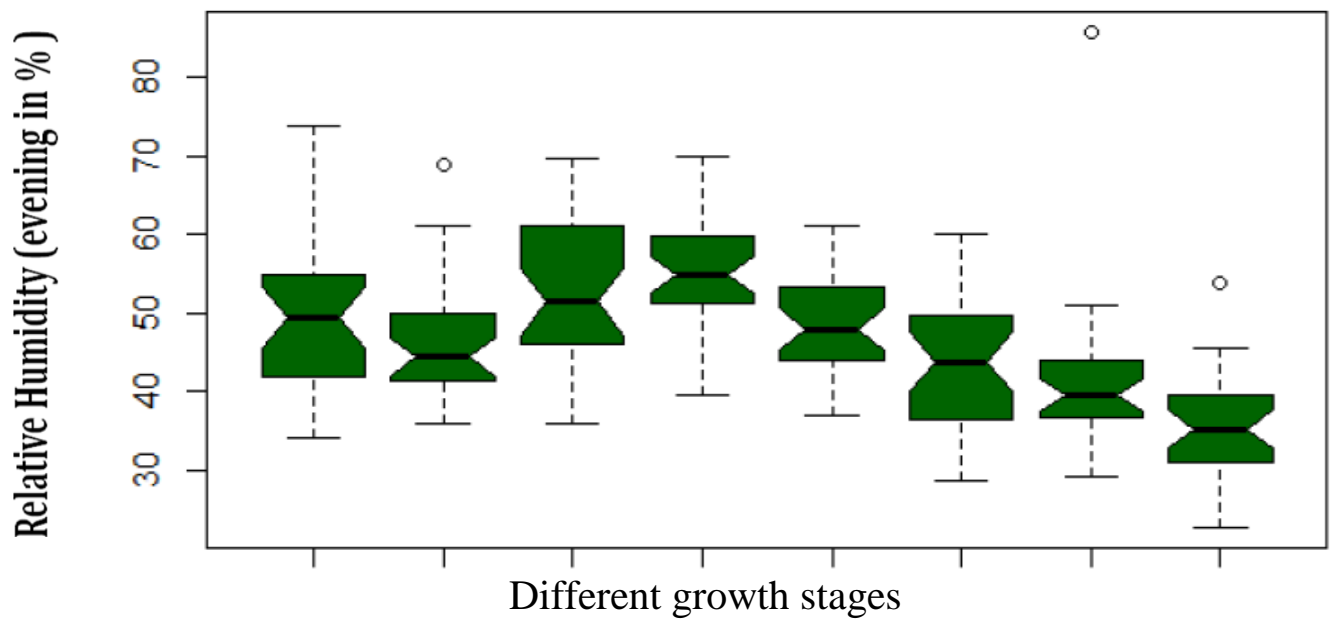

Fig.5 Box Plot of Rainfall (in mm) at Different Growth Stages

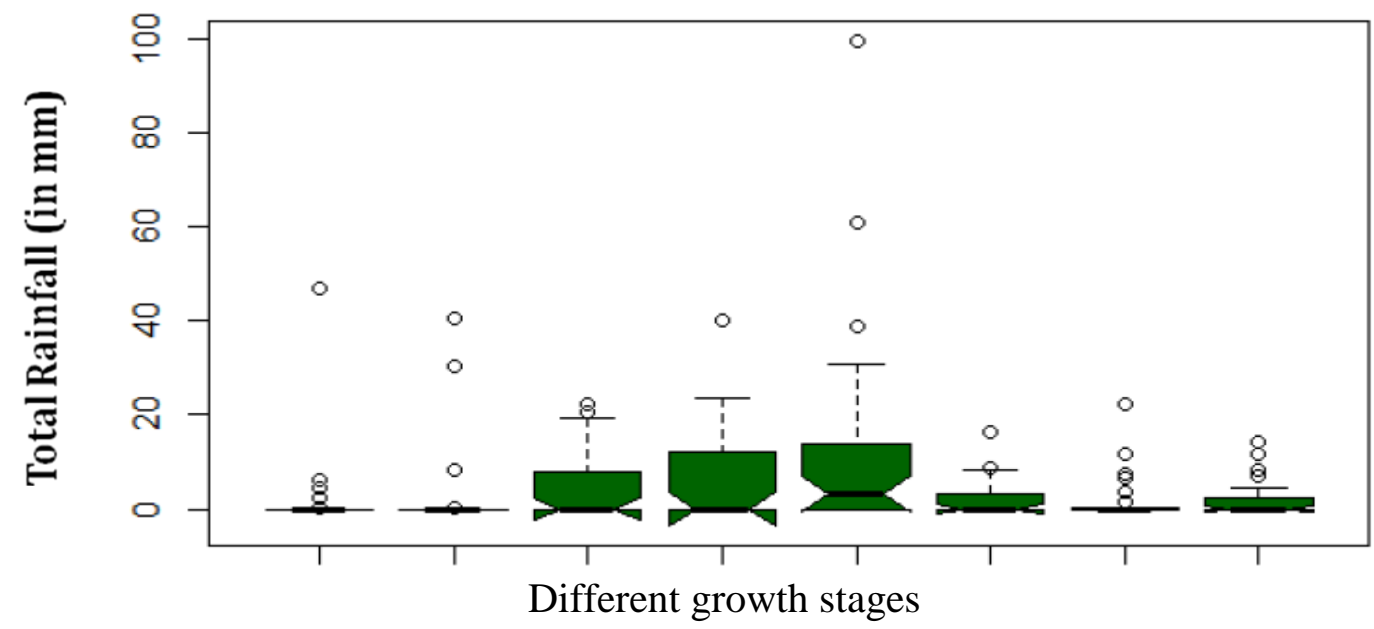

Fig.6 Box plot of evaporation (in \%) at different growth stages

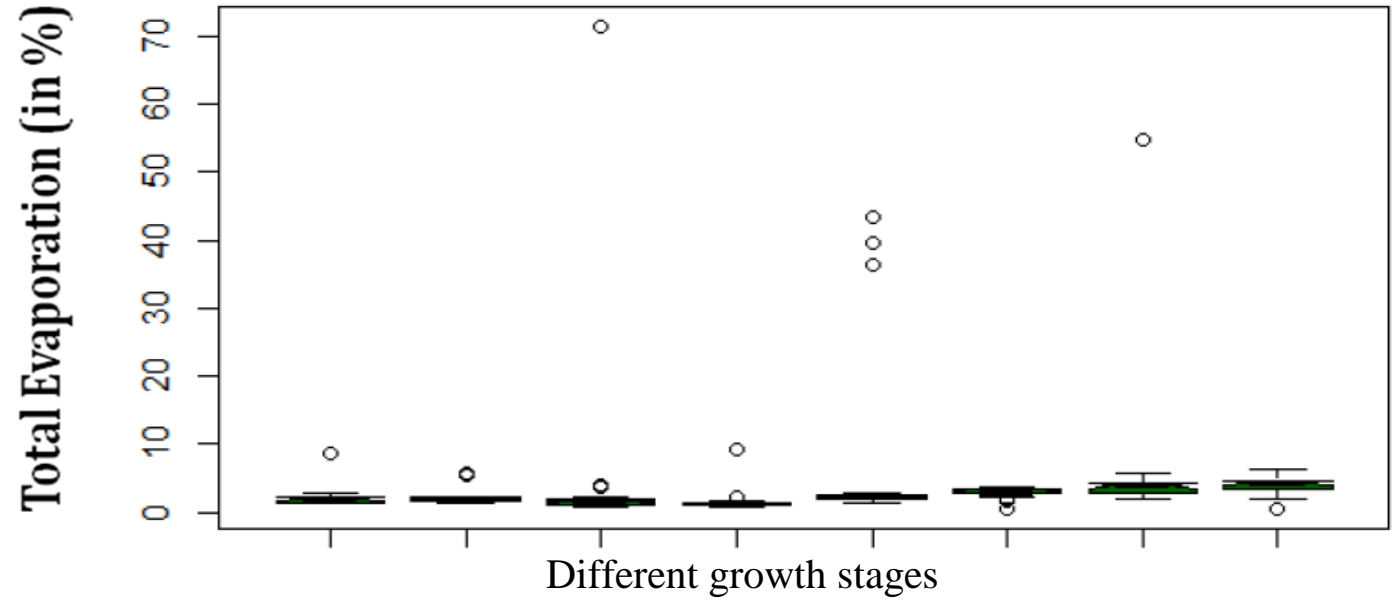




\section{Relative humidity in evening}

Figure 4 shows the Box Plot of Relative Humidity in Evening at different growth stages. Relative Humidity in evening (RH23.) has heavy tailed variable at node stage and a short tailed variable is at Relative Humidity in Evening (RH2-7). It means the Maximum variation of Relative Humidity in Evening at node stage and Minimum variation of Relative Humidity in Evening at dough stage respectively. Dots represent outliers. Outliers at dough stage, tillering stage and seedling emergence which shows that the beyond the bounds of the whiskers is more than the normal.

\section{Effect of rainfall}

Figure 5 shows the Box Plot of rainfall at different growth stages. Rainfall (RAIN-5) and (RAIN-4) has heavy tailed variable at ear head emergence stage and boot stage and a short tailed variable is at Rainfall (RAIN-7) and (RAIN-2). It means the Maximum variation of Rainfall at ear head emergence stage and boot stage and Minimum variation of Rainfall at dough stage and tillering stage respectively. Dots represent outliers. Outliers at ear head emergence stage which shows that the beyond the bounds of the whiskers which is more than the normal of seedling emergence stage, tillering stage, node stage, boot stage, milk stage, dough stage and maturity stage.

\section{Effect of evaporation}

Figure 6 shows the Box Plot of Evaporation at different Growth Stages. Evaporation of dough stage (EVAP-7) and maturity stage (EVAP-8) has heavy tailed variable and tillering stage and milk stage has a short tailed variable of Evaporation (EVAP-2) and (EVAP-6). It means the Maximum variation of Evaporation at dough stage and maturity stage and Minimum variation of Evaporation at tillering stage and milk stage respectively. Dots represent outliers. Outliers at ear head emergence which shows that the beyond the bounds of the whiskers is more than the normal of node stage, dough stage, boot stage, seedling emergence stage and tillering stage and outliers at milk stage and maturity stage is less than the normal.

In conclusion, the approach provided insight into the structure of interrelationships within the dataset more easily as compared to multiple regression modeling. Evaporation was found to be the most important variable in determining the yield variability at the stages: seedling emergence, boot stage and milk stage. At tillering, dough and maturity stages, morning relative humidity was identified as the most important variable in explaining the yield variability. Maximum temperature was identified as the most important variable at node and ear head emergence. Box plot presented a simple design to identify the importance of different weather variables at different stages which is expected to help in assessing the estimated impact of the variables at different growth stages of the crop which in turn will help to adopt preventive measures to deal with the adverse effects of change in weather

\section{References}

Aggarwal, P.K. (2000). Application of systems simulation for understanding and increasing yield potential of wheat and rice', Ph.D. Thesis, Wageningen University, Netherlands.

Easterling, W. E. (2007). "5.6.5 Food security and vulnerability". In ML Parry et al, (Eds.). Chapter 5: Food, Fiber, and Forest Products. Climate change 2007: impacts, adaptation and vulnerability: contribution of Working Group II to the fourth assessment report of the 
Intergovernmental Panel on Climate Change. Cambridge University Press $(C U P)$ : Cambridge, UK: Print version: CUP. This version: IPCC - ISBN 0-52188010-6.

Ewert, F., Rounsevell, M.D.A., Reginster, I., Metzger, M.G. and Leemans, R. (2005). Future scenarios of European agricultural land use. I. Estimating changes in crop productivity. Agriculture, Ecosystem and Environment. 107: 101-116.

IPCC: 2007. Climate Change (2007)Impacts, Adaptation and Vulnerability. Contribution of Working Group II to the Fourth Assessment Report of the Intergovernmental Panel on Climate Change. Parry, M.L., Canziani, O.F., Palutikof, J.P., Van der Linden P.J. and Hanson, C.E. (eds), Cambridge University Press, Cambridge.

Mall, R.K. and Singh, K.K. (2000). Climate variability and wheat yield progress in
Punjab using the CERESwheat and WTGROWS models. Yayu Mandal 30(3-4): 35-41.

Parry, M., Rosenzweig, C., Inglesias, A., Livermore, M. and Gischer, G. 2004. Effects of climate change on global food production under SRES emissions and socio-economic scenarios. Global Environment Change.14: 53-67.

Pathak, H., Ladha, Aggarwal, P. K., Peng, S., Das, S., Singh, Y., Singh, B., Kamra, S. K., Mishra, B., Sastri, A. S. R. A. S., Aggarwal, H. P., Das, D. K. and Gupta, R. K. (2003).Trends of climatic potential and on-farm yields of rice and wheat in the Indo-Gangetic Plains. Field Crops Research.80: 223-234.

Selvaraju, R. (2003).Impact of El NinoSouthern Oscillation on Indian food grain production. International Journal of Climatology. 23: 187-206.

\section{How to cite this article:}

Subhash Kumar, S.P. Singh, Mahesh Kumar and Abdus Sattar. 2018. Effect of Weather Variables on Wheat Yield by Different Stages of Wheat through Box Plot Design. Int.J.Curr.Microbiol.App.Sci. 7(05): 2383-2390. doi: https://doi.org/10.20546/ijcmas.2018.705.274 